\title{
Utilizing bycatch camera-trap data for broad-scale occupancy and conservation: a case study of the brown hyaena Parahyaena brunnea
}

\author{
Kathryn S. Williams, Ross T. Pitman, Gareth K. H. Mann \\ Gareth Whittington-Jones, Jessica Comley, Samual T. Williams \\ Russell A. Hill, Guy A. Balme and Daniel M. Parker
}

\begin{abstract}
With human influences driving populations of apex predators into decline, more information is required on how factors affect species at national and global scales. However, camera-trap studies are seldom executed at a broad spatial scale. We demonstrate how uniting finescale studies and utilizing camera-trap data of non-target species is an effective approach for broadscale assessments through a case study of the brown hyaena Parahyaena brunnea. We collated camera-trap data from 25 protected and unprotected sites across South Africa into the largest detection/non-detection dataset collected on the brown hyaena, and investigated the influence of biological and anthropogenic factors on brown hyaena occupancy. Spatial autocorrelation had a significant effect on the data, and was corrected using a Bayesian Gibbs sampler. We show that brown hyaena occupancy is driven by specific co-occurring apex predator species and human disturbance. The relative abundance of spotted hyaenas Crocuta crocuta and people on foot had a negative effect on brown hyaena occupancy, whereas the relative abundance of leopards Panthera pardus and vehicles had a positive influence. We estimated that brown hyaenas occur across $66 \%$ of the surveyed cameratrap station sites. Occupancy varied geographically, with
\end{abstract}

KatHRYN S. WiLLIAMS ${ }^{*} \dagger$ (Corresponding author, (D) orcid.org/0000-0002-68902196), Samual T. Williams $¥ \S$ (10) orcid.org/0000-0001-7205-7426) and Russell A. Hill $\ddagger$ (10 orcid.org/0000-0002-7601-5802) Department of Anthropology, Durham University, Dawson Building, South Road, Durham, DH1 3LE, UK. E-mail k.s.williams@durham.ac.uk

Ross T. Pitman I, Gareth K. H. Mann I, Gareth Whittington-Jones and GuY A. BalmE (10 orcid.org/0000-0002-3844-1720) Panthera, New York, USA

Jessica Comley (당 orcid.org/0000-0002-3043-7022) and Daniel M. Parker $\dagger$ (10) orcid.org/0000-0001-7555-5674) Wildlife and Reserve Management Research Group, Department of Zoology and Entomology, Rhodes University, Grahamstown, South Africa

${ }^{*}$ Also at: Primate and Predator Project, Louis Trichardt, South Africa $\dagger$ Also at: School of Biology and Environmental Sciences, University of Mpumalanga, Nelspruit, South Africa

¥Also at: Department of Zoology, University of Venda, Thohoyandou, South Africa

$\$$ Also at: Institute for Globally Distributed Open Research and Education, Johannesburg, South Africa

TAlso at: Institute for Communities and Wildlife in Africa, University of Cape Town, Rondebosch, South Africa

Received 18 February 2019. Revision requested 17 April 2019.

Accepted 11 June 2019. First published online 12 October 2020. lower estimates in eastern and southern South Africa. Our findings suggest that brown hyaena conservation is dependent upon a multi-species approach focussed on implementing conservation policies that better facilitate coexistence between people and hyaenas. We also validate the conservation value of pooling fine-scale datasets and utilizing bycatch data to examine species trends at broad spatial scales.

Keywords brown hyaena, camera trapping, carnivores, human-wildlife conflict, occupancy modelling, Parahyaena brunnea, spatial autocorrelation

Supplementary material for this article is available at doi.org/10.1017/So030605319000747

\section{Introduction}

Carnivore species across the globe are in decline (Ripple et al., 2014). With an increasing human population, the biological traits of carnivores put them at high risk of extinction (Cardillo et al., 2004). Although some smaller species are plentiful and adaptable, many larger carnivores are vulnerable to extinction as a result of their narrow geographical ranges, small and isolated populations, low genetic diversity, specialized niche requirements, large home ranges, and propensity to compete with humans for the apex of shared food webs (Gittleman et al., 2001; Sillero-Zubiri \& Laurenson, 2001). The key factors affecting carnivore survivorship are often interrelated; thus a connected and multifaceted approach is recommended in carnivore conservation (Winterbach et al., 2013).

Determining which factors influence species occupancy is vital for conservation, but this is often challenging for carnivores because of their secretive behaviour, nocturnal habits, low densities and broad spatial requirements that often extend beyond physical, administrative and political boundaries (Balme et al., 2010; Bischof et al., 2016; Chundawat et al., 2016). Camera traps are an increasingly popular tool in carnivore research and management because they overcome many of these obstacles (McCallum, 2013). They are affordable, can be deployed over large areas, and are able to collect continuous data non-invasively on even the most cryptic species. Accordingly, camera traps have 
the capacity to monitor species and inform conservation strategies at both national and global scales (Ahumada et al., 2016).

Despite this potential, few studies have examined carnivore occupancy, and the factors influencing occupancy, beyond the scale of single study sites (but see Karanth et al., 2011; Pitman et al., 2017a; Miller et al., 2018). This localized approach to monitoring generates a limited, and potentially biased, view of species ecology and behaviour. Recent collaborations have shown, however, that robust broad-scale species assessments are possible if researchers combine datasets from several single-site camera-trap surveys (e.g. Linkie et al., 2007; Miller \& Grant, 2015; Tan et al., 2017). In addition, although many camera-trap surveys are established to monitor a single species, they also collect data on non-target species (Linkie et al., 2013). Such bycatch data can contribute towards assessments of non-target species if spatial violations are accounted for (Edwards et al., 2018). Occupancy modelling is forgiving of non-homogenous survey parameters and imperfect detection, and is therefore ideal for broad-scale collaborative analyses (MacKenzie et al., 2006). Occupancy modelling estimates the proportion of areas occupied by target species, and assesses which parameters affect utilization, through the examination of detection/ non-detection data. Camera traps are ideal for collecting such data (O'Connell \& Bailey, 2011). Compensating for potential false absences is an essential function of occupancy analysis, which distinguishes between a naïve occupancy estimate and the best estimate of true occupancy (MacKenzie et al., 2006).

A wide range of environmental, biological and anthropogenic factors can affect occupancy. In many cases, parameters associated with human disturbance and intraguild relationships have a greater influence on carnivore occupancy than environmental covariates (Schuette et al., 2013; Strampelli et al., 2018; Wang et al., 2018). For species that increasingly inhabit human-modified landscapes, a deeper exploration of how biological and anthropogenic factors affect occupancy is required.

We used camera trapping and single-season, singlespecies occupancy modelling to examine factors affecting brown hyaena Parahyaena brunnea occupancy across its South African range. Humans pose both direct and indirect threats to carnivores through habitat loss and degradation, prey depletion and poaching (Ripple et al., 2014). Private land used for farming comprises a large proportion of brown hyaena range, and is vital to their survival (Kent \& Hill, 2013). Despite their ability to survive outside protected areas and in close proximity to people (e.g. Kuhn, 2014), brown hyaenas are subject to anthropogenic pressures, causing the species, which is categorized as Near Threatened, to come close to qualifying as threatened on the IUCN Red List (Wiesel, 2015). At present, research on brown hyaenas is predominately limited to geographically scattered, small-scale studies. As a nocturnal and cryptic species, there is a paucity of data on the parameters affecting the species occupancy on a broader scale (Yarnell et al., 2016). By compiling data from 25 surveys into the largest detection/ non-detection dataset collected on the species, our study makes a critical step towards filling this gap in ecological knowledge for protected areas and areas used for ecotourism. We also aim to demonstrate the potential for data initially collected to examine one target species, the leopard Panthera pardus, to provide a broadscale assessment of a bycatch species, the brown hyaena.

\section{Study area}

We collated data on brown hyaena detection and non-detection from 25 camera-trap surveys conducted across South Africa during 2013-2017 (Fig. 1, Table 1, Supplementary Material 1). The area surveyed totalled $7,705 \mathrm{~km}^{2}$. Camera-trap survey sites within and outside formally protected areas were represented ( 21 formally protected sites and 4 privately protected sites). Although sites are either designated as protected areas by IUCN (UNEP-WCMC, 2018; Supplementary Table 1) or privately prioritize the conservation of native species, sections of KwaZulu Private Game Reserve and adjacent private properties, Lajuma and adjacent private properties, and Little Karoo are unprotected. All but three sites are fenced (Supplementary Material 1). However, even electrified perimeters are often permeable and brown hyaenas in protected areas may occupy home ranges that also include unprotected areas (Kesch et al., 2013, 2015; Miller et al., 2018).

An array of Panthera V-Series camera traps (models V4, $V_{5}$ and V6; Panthera, New York, USA) monitored all sites except Mountain Zebra National Park, where Cuddeback Attack camera traps (Greenbay, Wisconsin, USA) were used. The location and spacing of camera stations was optimized for estimation of leopard population density using a spatially explicit capture-recapture framework at all sites other than Mountain Zebra National Park. The mean distance between camera-trap stations was $2.04 \pm$ SD $0.58 \mathrm{~km}$ and stations were dispersed evenly across survey sites. Camera stations consisted of pairs of camera traps mounted on poles or trees c. $40 \mathrm{~cm}$ above the ground, and $2-3 \mathrm{~m}$ from a road or trail. Camera stations were visited weekly or fortnightly to download images, change batteries and maintain the cameras. Although most surveys were initially established for leopard population monitoring, camera traps were placed in locations with a reasonable probability of detecting brown hyaenas but without guarantee of detection, thus reducing false absences and adhering to the requirements of occupancy analysis (Mackenzie \& Royle, 2005; MacKenzie et al., 2006). Comparable detection probability for leopards and brown hyaenas was based on a similar 


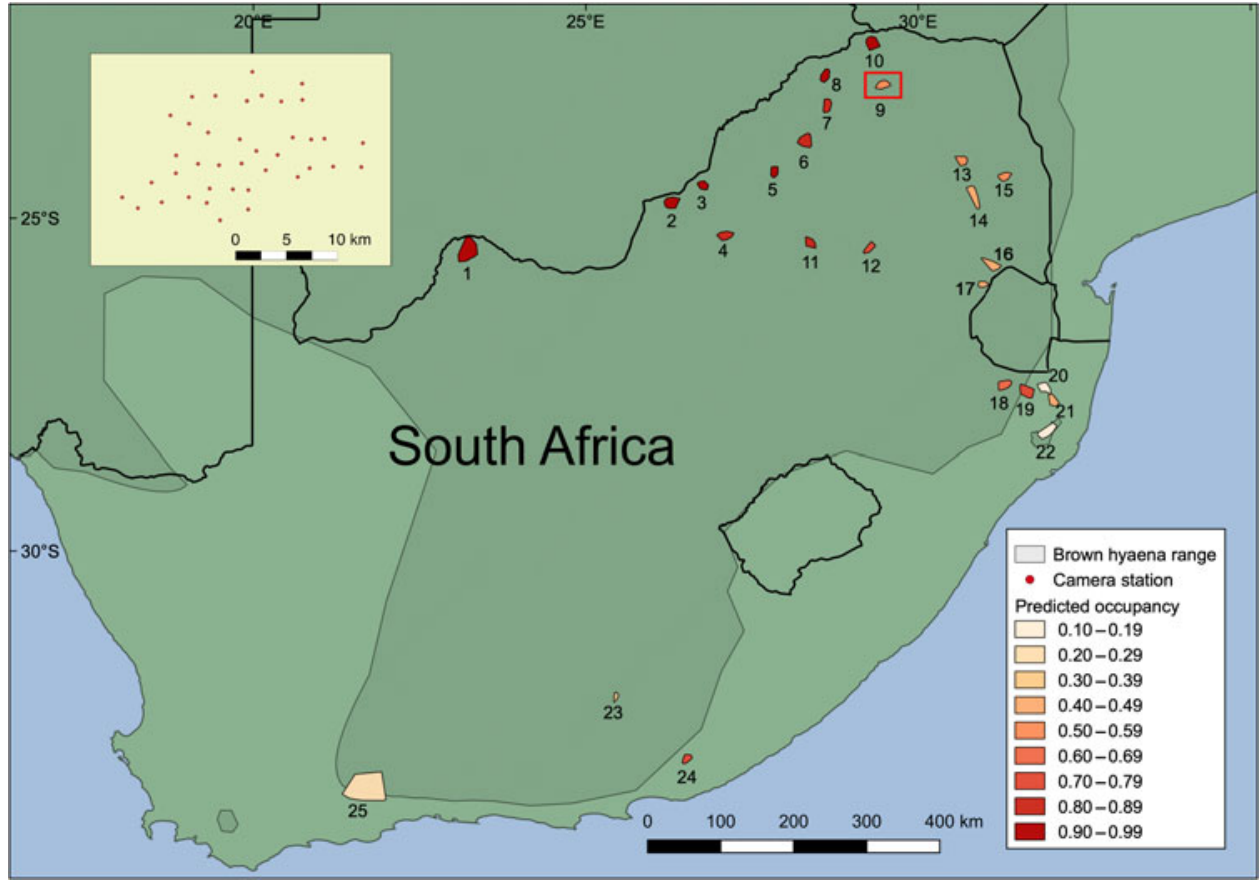

FIG. 1 Locations of the 25 camera-trap survey sites used to assess brown hyaena Parahyaena brunnea occupancy in South Africa. Names of numbered sites are in Table 1. Inset map shows camera station placement at one of the sites (no. 9, Lajuma and adjacent private properties) as an example. Brown hyaena range is from Wiesel (2015). Some of the survey sites lie outside this range (the global scale of the IUCN map lacks fine scale precision).

Graduated shading of survey sites indicates predicted brown hyaena occupancy estimates averaged from camera-trap station estimates. shoulder height (Estes, 1991), a preference by both species for travelling on roads and trails (Mann et al., 2015; Welch et al., 2016), and a high photographic capture rate. We tested photographic capture rate of hyaenas and leopards by placing a Reconyx Hyperfire HC60o no-glow infrared camera trap (Holmen, Wisconsin, USA), which has the fastest trigger speed and recovery time available (Trolliet et al., 2014), $2 \mathrm{~m}$ from the camera traps at one survey site (Lajuma and adjacent private properties). We detected a similar photographic rate using both models, thus confirming that all animals were detected despite brown hyaenas generally moving faster to cover larger daily distances than leopards (Mills, 1990; Swanepoel, 2008; Martins \& Harris, 2013; Williams, 2017).

\section{Methods}

Four key categories of site covariates (habitat; relative sympatric predator abundance; human activity, e.g. people on foot and vehicles; relative abundance of medium- and large-sized prey species) were quantified from camera-trap and habitat data (Table 2). Habitat classifications from Department of Environmental Affairs Republic of South Africa (2015) were assigned to each camera-trap station using the Point Sampling Tool in QGIS 3.0.1 (QGIS Development Team, 2018). Apex predator abundance was determined individually for cheetah Acinonyx jubatus, spotted hyaena Crocuta crocuta, leopard, lion Panthera leo and African wild $\operatorname{dog}$ Lycaon pictus. Prey with an average female weight of $15-50 \mathrm{~kg}$ were defined as medium-sized and those
$>50 \mathrm{~kg}$ were considered large-sized (following Mills \& Mills, 1978). Small-bodied species have lower detection frequencies on camera traps (Henschel et al., 2011) and do not comprise a large proportion of brown hyaena diet (Williams et al., 2018), hence their exclusion. To ensure statistical independence between photographic events and to create a comparable baseline, consecutive photographs of the same species at the same station within 30 minutes were excluded (O'Brien et al., 2003). Species and human activity abundance were calculated using a relative abundance index: the number of single capture events per 100 camera-trap days (Treves et al., 2010; Carter et al., 2012). Site covariates with continuous relative abundance index values were standardized as z-scores because of the large range of values present (Harihar \& Pandav, 2012).

To avoid multicollinearity disrupting clear outcomes in regards to detection probabilities (MacKenzie \& Bailey, 2004), we tested relationships between each pair of covariates for multicollinearity, in $R$ 3.4.3 (R Development Core Team, 2017), using Spearman's rank correlation tests, and confirmed outcomes using the $R$ package VIF (Lin et al., 2011). Any pairwise correlation coefficients with Rho $>0.6$ in the same model were considered correlated and one covariate was excluded (Tan et al., 2017). Covariates with a variance inflation factor $<3$ were retained (Wang et al., 2018).

Brown hyaena detection histories, with values of o (nondetection) and 1 (detection), were created to reflect the presence of brown hyaenas at each camera-trap station on each day of the survey. To meet the assumption of a closed population (Rota et al., 2009), data from only the first 40 days of each survey were used. The average number of days per 
TABLE 1 Details of the first 40 days of camera-trap surveys for the brown hyaena Parahyaena brunnea at the 25 sites in the Eastern Cape, Gauteng, KwaZulu-Natal, Limpopo, Mpumalanga, North West, and Western Cape provinces of South Africa (Fig. 1). No. refers to the numbered sites in Fig. 1.

\begin{tabular}{|c|c|c|c|c|c|c|}
\hline No. & Survey site & $\begin{array}{l}\text { Area } \\
\left(\mathrm{km}^{2}\right)\end{array}$ & Year & $\begin{array}{l}\text { No. of } \\
\text { stations }\end{array}$ & $\begin{array}{l}\text { Effort } \\
\text { (trap-nights) }\end{array}$ & $\begin{array}{l}\text { No. of brown } \\
\text { hyaena captures }\end{array}$ \\
\hline 1 & Khamab Kalahari Reserve & 617 & 2016 & 40 & 1,592 & 339 \\
\hline 2 & Madikwe Game Reserve & 327 & 2016 & 40 & 1,586 & 322 \\
\hline 3 & Atherstone Nature Reserve & 156 & 2013 & 50 & 2,000 & 359 \\
\hline 4 & Pilanesberg National Park & 247 & 2016 & 40 & 1,584 & 596 \\
\hline 5 & Welgevonden Private Game Reserve & 146 & 2013 & 51 & 1,958 & 202 \\
\hline 6 & Lapalala Wilderness & 385 & 2016 & 40 & 1,571 & 225 \\
\hline 7 & Wonderkop Nature Reserve & 192 & 2013 & 52 & 2,032 & 116 \\
\hline 8 & Zingela Nature Reserve & 186 & 2016 & 40 & 1,550 & 238 \\
\hline 9 & Lajuma and adjacent private properties & 193 & 2014 & 39 & 1,560 & 104 \\
\hline 10 & Venetia Limpopo Nature Reserve & 288 & 2016 & 40 & 1,583 & 135 \\
\hline 11 & Dinokeng Game Reserve & 173 & 2016 & 36 & 1,440 & 44 \\
\hline 12 & Loskop Dam Nature Reserve & 170 & 2016 & 34 & 1,359 & 63 \\
\hline 13 & Makalali Private Game Reserve & 180 & 2015 & 40 & 1,513 & 54 \\
\hline 14 & Blyde River Canyon Nature Reserve & 232 & 2016 & 31 & 1,200 & 1 \\
\hline 15 & Timbavati Game Reserve & 167 & 2016 & 40 & 1,545 & 5 \\
\hline 16 & Barberton Nature Reserve & 280 & 2016 & 33 & 906 & 6 \\
\hline 17 & Songimvelo Game Reserve & 112 & 2016 & 27 & 1,027 & 45 \\
\hline 18 & Ithala Game Reserve & 236 & 2013 & 36 & 1,378 & 193 \\
\hline 19 & KwaZulu Private Game Reserve and adjacent private properties & 325 & 2015 & 62 & 2,417 & 342 \\
\hline 20 & Somkhanda Game Reserve and adjacent properties & 229 & 2014 & 39 & 1,435 & 5 \\
\hline 21 & Manyoni Private Game Reserve & 200 & 2015 & 40 & 1,593 & 35 \\
\hline 22 & Hluhluwe-iMfolozi Park & 418 & 2017 & 46 & 1,632 & 8 \\
\hline 23 & Mountain Zebra National Park & 73 & 2014 & 11 & 440 & 24 \\
\hline 24 & Kwandwe Private Game Reserve & 135 & 2017 & 40 & 1,278 & 146 \\
\hline 25 & Little Karoo & 2,038 & 2017 & 40 & 1,577 & 6 \\
\hline
\end{tabular}

${ }^{1}$ Minimum convex polygon covered by camera-trap stations.

survey was 48 excluding Mountain Zebra National Park ( 367 days). The global model was tested for goodness-of-fit with detection histories collapsed into intervals of 4-7 days (MacKenzie \& Bailey, 2004). Collapsing detection histories into eight 5-day intervals resulted in the lowest overdispersion statistic $(\hat{c})$ value, thus maximizing model fit (Supplementary Table 2). This length of time did not overcompress the statistical power of the data, accurately represented the rarity of the study species, and was in line with other large carnivore occupancy studies (Negrões et al., 2010; O'Connell \& Bailey, 2011).

A two-step approach was used to examine factors influencing brown hyaena occupancy. In the first stage, singleseason single-species occupancy analysis was conducted using the $R$ package unmarked $0.12-2$ (Fiske \& Chandler, $2011)$, to test the effect of covariates on occupancy $(\psi)$ and probability of detection $(p)$ without spatial autocorrelation. The effect of survey covariates were modelled on the probability of detection (Long et al., 2011). During this stage we identified site covariates to test during the second stage, a multivariate analysis with spatial autocorrelation.

Models were ranked using Akaike's information criterion (AIC), with higher-ranking models receiving the lowest AIC values (Burnham \& Anderson, 1998). The global model was assessed for goodness-of-fit using Pearson $\chi^{2}$ tests (MacKenzie \& Bailey, 2004) and normal dispersion using $\hat{c}$. Sites with an inflated $\hat{c}$ value were removed to improve the goodness-of-fit before re-running the occupancy analysis (Meredith, 2008).

Summed model weights for biological and anthropogenic covariates $>0.10$ were calculated to determine which covariates should be analysed for spatial autocorrelation in the next stage (Schuette et al., 2013; Tan et al., 2017). Summed model weights $\geq 0.5$ showed a strong response and were retained (Barbieri \& Berger, 2004).

The retained covariates were modelled for spatial autocorrelation in the second stage. By collating data from multiple sites in which the spacing of camera traps was optimized for another species, our dataset is likely to violate the assumption of independence between sampling sites in occupancy modelling and to suffer from spatial autocorrelation (Legendre, 1993; MacKenzie et al., 2002), especially given the tendency of brown hyaenas to travel up to $50 \mathrm{~km}$ per night (Mills, 1990). Spatial autocorrelation assumes that neighbouring camera stations have a greater likelihood of sharing a characteristic than more distant camera 
TABLE 2 Site covariates for modelling brown hyaena occupancy across South Africa. Parameter and expected influence is provided for occupancy $(\psi)$ where applicable.

\begin{tabular}{|c|c|c|c|c|}
\hline Name & Description & Category $^{1}$ & Source & $\begin{array}{l}\text { Parameter and ex- } \\
\text { pected influence }\end{array}$ \\
\hline Habitat & Categorical, 35 land-cover classes & Habitat & $\begin{array}{l}\text { 2013-2014 South African National } \\
\text { Land-Cover Dataset: DEA-CARDNO } \\
\text { SCFP } 002^{2}\end{array}$ & $\psi\left({ }^{*}\right)$ \\
\hline $\begin{array}{l}\text { Cheetah } \\
\text { Acinonyx jubatus }\end{array}$ & $\begin{array}{l}\text { Numeric, detection frequency of } \\
\text { cheetahs per } 100 \text { trap-days }\end{array}$ & Predator & Camera trap & $\psi(+)$ \\
\hline $\begin{array}{l}\text { Spotted hyaena } \\
\text { Crocuta crocuta }\end{array}$ & $\begin{array}{l}\text { Numeric, detection frequency of } \\
\text { spotted hyaenas per } 100 \text { trap-days }\end{array}$ & Predator & Camera trap & $\psi(-)$ \\
\hline $\begin{array}{l}\text { Leopard } \\
\quad \text { Panthera pardus }\end{array}$ & $\begin{array}{l}\text { Numeric, detection frequency of } \\
\text { leopards per } 100 \text { trap-days }\end{array}$ & Predator & Camera trap & $\psi(+)$ \\
\hline $\begin{array}{l}\text { Lion } \\
\quad \text { Panthera leo }\end{array}$ & $\begin{array}{l}\text { Numeric, detection frequency of } \\
\text { lions per } 100 \text { trap-days }\end{array}$ & Predator & Camera trap & $\psi(-)$ \\
\hline $\begin{array}{l}\text { Wild dog } \\
\text { Lycaon pictus }\end{array}$ & $\begin{array}{l}\text { Numeric, detection frequency of } \\
\text { African wild dogs per } 100 \text { trap-days }\end{array}$ & Predator & Camera trap & $\psi(+)$ \\
\hline Human & $\begin{array}{l}\text { Numeric, detection frequency of } \\
\text { human foot traffic per } 100 \text { trap-days }\end{array}$ & $\begin{array}{l}\text { Human } \\
\text { disturbance }\end{array}$ & Camera trap & $\psi(-)$ \\
\hline Vehicle & $\begin{array}{l}\text { Numeric, detection frequency of } \\
\text { vehicles per } 100 \text { trap-days }\end{array}$ & $\begin{array}{l}\text { Human } \\
\text { disturbance }\end{array}$ & Camera trap & $\psi(-)$ \\
\hline Prey & $\begin{array}{l}\text { Numeric, detection frequency of } \\
\text { medium and large prey species } \\
\text { per } 100 \text { trap-days }\end{array}$ & $\begin{array}{l}\text { Prey } \\
\text { abundance }\end{array}$ & Camera trap & $\psi(+)$ \\
\hline
\end{tabular}

${ }^{1}$ Predator represents sympatric predator abundance.

${ }^{2}$ Department of Environmental Affairs Republic of South Africa (2015).

${ }^{3}$ Based upon average adult female weights and groups given by Mills \& Mills (1978). Mean adult female weights from Skinner \& Chimimba (2005).

*We expect this variable to be important, but as it is ordinal it is not meaningful to predict an overall direction.

stations, and can produce overestimated precision in occupancy estimates and underestimated standard errors (Latimer et al., 2006; Johnson et al., 2013).

Spatial autocorrelation was addressed by fitting Bayesian versions of the candidate set using the package stocc 1.2.3 (Johnson, 2015) in $R$. A restricted spatial regression model was used to assess occupancy on all combinations of covariates with a summed model weight $\geq 0.5$ (Broms et al., 2014).

The threshold for distinguishing spatial structure between camera-trap stations was set to $6.15 \mathrm{~km}$, the mean radius of a brown hyaena home range, established from averaged brown hyaena home range estimates taken from 13 collared individuals in five of the survey sites (Supplementary Table 3). The Moran cut was 92.5 (0.1 $\times$ number of camera-trap stations, following Hughes \& Haran, 2013). The detection and occupancy processes were assigned flat prior distributions with a Gamma distribution of 0.5 and 0.0005 (Johnson et al., 2013; Wang et al., 2018). The Gibbs sampler for each Bayesian model ran for 200,000 Markov-Chain Monte Carlo iterations with a burn-in period of 50,000 and a thinning rate of 10 . Covariates with a $95 \%$ Bayesian credible interval that did not overlap zero were considered to have a significant association with brown hyaena occupancy (Wang et al., 2018). Model parameter convergence was assessed using Geweke diagnostic statistics and the $|Z|<1.96$ scores (Wang et al.,
2018). The posterior predictive loss criterion (Gelfand \& Ghosh, 1998) was compared between the Bayesian restricted spatial regression and non-spatial models for positive spatial autocorrelation.

Robustness for the restricted spatial regression model was assessed using the area under the curve (AUC) statistic (Broms et al., 2014; Wang et al., 2018). We inputted the median occurrences and spatially corrected $\psi$ estimates at each camera-trap station with the package ROCR (Sing et al., 2005) in $R$ to determine the AUC statistic.

\section{Results}

After removing 19 stations that captured brown hyaenas during every 5-day sampling interval (Supplementary Table 4 ), to reduce overdispersion, the final occupancy survey included 965 camera-trap stations and totalled 36,999 cameratrap days. Brown hyaenas were recorded at 630 camera-trap stations for a total of 2,862 independent capture events, resulting in an overall naïve occupancy of 0.65 .

Effort and survey site affected probability of detection (Table 3). No covariates displayed multicollinearity so all were retained in the subsequent analyses $(r<0.6$ and variance inflation factor $<3$ ). Models with $\triangle \mathrm{AIC}<2$ were included in the candidate set (Table 4 ). The global model 
TABLE 3 Brown hyaena detection probability $(p)$ models.

\begin{tabular}{|c|c|c|c|c|c|}
\hline & $\mathrm{AIC}^{1}$ & $\Delta \mathrm{AIC}^{2}$ & $\mathrm{AICwt}^{3}$ & $K^{4}$ & $-211^{5}$ \\
\hline$p$ (effort + site) & $6,962.54$ & 0.00 & 0.68 & 27 & $6,908.54$ \\
\hline$p$ (effort + site + habitat $)$ & $6,964.01$ & 1.47 & 0.32 & 28 & $6,908.01$ \\
\hline$p$ (site) & $7,025.85$ & 63.31 & 0.00 & 26 & $6,973.85$ \\
\hline$p$ (site + habitat $)$ & $7,027.16$ & 64.62 & 0.00 & 27 & $6,973.16$ \\
\hline$p$ (effort + habitat $)$ & $7,664.26$ & 701.72 & 0.00 & 4 & $7,656.26$ \\
\hline$p$ (effort) & $7,672.35$ & 709.81 & 0.00 & 3 & $7,666.35$ \\
\hline$p$ (habitat) & $7,721.19$ & 758.65 & 0.00 & 3 & $7,715.19$ \\
\hline$p()$. & $7,730.18$ & 767.64 & 0.00 & 2 & $7,726.18$ \\
\hline
\end{tabular}

${ }^{1}$ Akaike's information criterion.

${ }^{2}$ Difference in AIC between each model and top ranking model.

${ }^{3}$ AIC weight.

${ }^{4}$ Number of parameters.

${ }^{5}$ Twice the negative log-likelihood.

TABLE 4 Top ranked site occupancy models for brown hyaena occupancy $(\psi)$ in South Africa.

\begin{tabular}{|c|c|c|c|c|c|}
\hline Model & $\mathrm{AIC}^{1}$ & $\Delta \mathrm{AIC}^{2}$ & $\mathrm{AICwt}^{3}$ & $K^{4}$ & $-211^{5}$ \\
\hline$\psi($ Cheetah + Spotted hyaena + Leopard + Lion + Wild dog + Human + Vehicle $)$ & $7,685.20$ & 0.00 & 0.33 & 9 & $7,667.20$ \\
\hline$\psi($ Cheetah + Spotted hyaena + Leopard + Lion + Wild dog + Human + Vehicle + Prey $)$ & $7,686.08$ & 0.88 & 0.21 & 10 & $7,666.08$ \\
\hline$\psi($ Cheetah + Spotted hyaena + Leopard + Lion + Wild dog + Human + Vehicle + Habitat $)$ & $7,687.03$ & 1.83 & 0.13 & 10 & $7,667.03$ \\
\hline
\end{tabular}

${ }^{1}$ Akaike's information criterion.

${ }^{2}$ Difference in AIC between each model and top ranking model.

${ }^{3}$ AIC weight.

${ }^{4}$ Number of parameters.

${ }^{5}$ Twice the negative log-likelihood.

fitted the data well $(\hat{c}=1.21)$. Site covariates relating to the five sympatric predator, human and vehicle abundance had summed model weights $>0.5$, and these were retained for the next stage of analysis (Table 5). Habitat and prey fell below this threshold and were therefore discarded from the second phase.

The restricted spatial regression model was more parsimonious than the non-spatial model (posterior predictive loss criterion: $2,606.07 \mathrm{vs} 2,790.45$ ), confirming that positive spatial autocorrelation influenced the data. Spotted hyaena and human abundance had a negative impact on brown hyaena occupancy, and leopard and vehicle abundance had a positive influence on brown hyaena occupancy (Table 6, Fig. 2).

Brown hyaenas are estimated to occur across $66 \%$ of the total sites surveyed $(\psi=0.66 \pm$ SE 0.09$)$ with site occupancy probability estimates of 0.12-0.98 (Supplementary Table 5). The majority of sites in eastern and southern South Africa had a lower mean occupancy estimate than those further north (Fig. 1). The AUC value was 0.74 for the restricted spatial regression model, suggesting reasonable levels of accuracy in our predictions of occupancy.

\section{Discussion}

Our study used a detection/non-detection dataset to identify, with a high level of confidence, a suite of four biological and anthropogenic factors that influence brown hyaena occupancy at a national scale. These findings suggest that camera-trap data focused on one species can provide useful data to determine broadscale occupancy trends of other, non-target species, provided the species share habitats and have similar-scale home range sizes. Our study enables us to make generalizations about variables influencing occupancy of brown hyaenas on a scale not previously possible for the species. The 25 survey sites incorporated a diverse array of environmental, biological, and anthropogenic conditions that are found throughout their international range. Our results therefore have conservation management implications applicable across the global range of the species, especially in protected areas and areas used for ecotourism.

The relative abundance of sympatric apex predators had the strongest influence on brown hyaena occupancy. Spotted hyaena relative abundance had a strong negative impact on brown hyaena occupancy, whereas the relative abundance of leopards showed a positive relationship with brown hyaena occupancy. Sympatric carnivore density estimations were not available as covariates in this study. We encourage future research to test brown hyaena occupancy against predator densities. Although relative abundance indices are not a substitute for density (Jennelle et al., 2002), relationships between brown hyaena occupancy and sympatric predator relative abundance mirror trends found when brown hyaenas cohabit with high densities of dominant 
TABLE 5 Summed model weights of site covariates (Table 2) tested for brown hyaena occupancy $(\psi)$ in South Africa.

\begin{tabular}{ll}
\hline Covariate & Summed model weights \\
\hline Spotted hyaena & 1.00 \\
Leopard & 1.00 \\
Vehicle & 0.99 \\
Cheetah & 0.97 \\
Human & 0.95 \\
Lion & 0.83 \\
Wild dog & 0.81 \\
Prey & 0.37 \\
Habitat & 0.26 \\
\hline
\end{tabular}

competitors. Spotted hyaenas present a competitive threat to the more submissive brown hyaena, through kleptoparasitism and occasionally as a source of mortality (Mills, 1990). Mills \& Mills (1982) similarly showed that brown hyaenas avoided areas of high spotted hyaena density in the southern Kalahari, regardless of prey abundance. This negative relationship may explain why brown hyaena mean occupancy was lowest at survey sites in eastern South Africa. Many of the eastern sites support healthy populations of dominant competitors such as spotted hyaenas and lions. High densities of dominant predators can restrict the success of subordinate predators such as African wild dogs, brown hyaenas and cheetahs (Mills \& Gorman, 1997; Marker et al., 2010).

The negative interspecific relationship and spatial separation between spotted and brown hyaenas can largely be attributed to environmental adaptability and diet. Brown hyaenas have a catholic and opportunistic diet, a secretive nature and low water requirements, which have enabled the species to survive in areas where less adaptable carnivores cannot persist (Maude, 2005). Spotted hyaenas, although also adaptable, have less plasticity in their habitat and prey requirements (Hayward, 2006; Schuette et al., 2013) and are highly vulnerable to persecution by humans on unprotected land, especially on livestock farms (Mills \& Hofer, 1998). The brown hyaena's adaptability in diet and habitat requirements probably explains why we found that habitat characteristics and prey abundance had little effect on brown hyaena occupancy, as in other studies (Thorn et al., 2009; Williams, 2017).

Alternatively, some sympatric predators do not present a direct threat to brown hyaenas and may instead have a positive effect on brown hyaena success. The positive relationship we detected between relative leopard abundance and brown hyaena occupancy may be attributed to the environment leopards inhabit and their potential to provide a food source for scavengers. Leopards prefer areas away from urban development with few competitive apex predators and a high prey abundance (Gavashelishvili \& Lukarevskiy, 2008; Steinmetz et al., 2013; Strampelli et al., 2018), and thus their presence may reflect more secure living
TABLE 6 Parameter estimates and 95\% credible intervals from a restricted spatial regression model assessing brown hyaena occupancy in South Africa. Beta coefficient estimates for each of the standardized covariates are reported as mean and standard deviation. Covariates with a $95 \%$ credible interval not overlapping zero are marked in bold to indicate there is a significant association between the covariate and brown hyaena occupancy. Model convergence was assessed using Geweke diagnostic statistics and the $|Z|<1.96$ score.

\begin{tabular}{lrcr}
\hline Covariate & \multicolumn{3}{l}{$95 \%$ Credible } \\
\hline (Intercept) & $0.97 \pm 0.13$ & $(\mathbf{0 . 7 2}, \mathbf{1 . 2 3})$ & -1.54 \\
Cheetah & $0.26 \pm 0.22$ & $(-0.06,0.67)$ & -0.84 \\
Spotted hyaena & $-0.42 \pm 0.09$ & $(-\mathbf{0 . 6 0},-\mathbf{0 . 2 5})$ & 1.43 \\
Leopard & $0.15 \pm 0.08$ & $(\mathbf{0 . 0 0}, \mathbf{0 . 3 0})$ & -0.60 \\
Lion & $0.17 \pm 0.10$ & $(-0.03,0.38)$ & -0.45 \\
Wild dog & $0.06 \pm 0.10$ & $(-0.14,0.27)$ & -0.32 \\
Human & $-0.21 \pm 0.06$ & $(\mathbf{- 0 . 3 3}, \mathbf{0 . 0 9})$ & 0.30 \\
Vehicle & $0.24 \pm 0.08$ & $(\mathbf{0 . 0 8}, \mathbf{0 . 4 1})$ & -0.31 \\
\hline
\end{tabular}

conditions for brown hyaenas. In addition, the brown hyaena is a poor hunter, and typically depends on scavenging to meet c. $95 \%$ of its dietary intake (Mills, 1984; Maude \& Mills, 2005). It therefore relies on other large carnivores, such as the leopard, to kill larger prey species (Stein et al., 2013; Mills, 2015). In areas where leopards are present, brown hyaenas have a similar diet (Stein et al., 2013; Williams et al., 2018), which can be explained by a high frequency of observed scavenging incidents from leopard kills (76\%; Stein et al., 2013).

Another factor that influences brown hyaena occupancy is anthropogenic activity. Brown hyaena occupancy was lower in areas with high human foot traffic. A similar trend was detected on private land in northern Limpopo Province, South Africa, where brown hyaena occupancy in unprotected farmland was negatively affected by high disturbance by people on foot (Williams, 2017). Striped hyaenas Hyaena hyaena also avoid human disturbance, with higher occupancy in rugged areas devoid of human activity and in areas with the greatest distance from human habitation (Singh et al., 2014). This finding fits well with the declines observed in carnivore populations globally as a result of human activity (Ripple et al., 2014).

Our finding that vehicle activity positively influenced brown hyaena occupancy was unanticipated, as we expected the abundance of vehicles to affect brown hyaena occupancy in the same manner as the relative abundance of people on foot. People on foot could represent threats to hyaenas such as poaching, legal hunting or control of damage causing animals, in addition to less threatening ecotourism or more general human activity. In contrast, vehicle-based ecotourism is conducted across many of our survey sites, and in these areas vehicles movements predominantly occur during the day, when brown hyaenas are resting, and thus pose a low risk. 

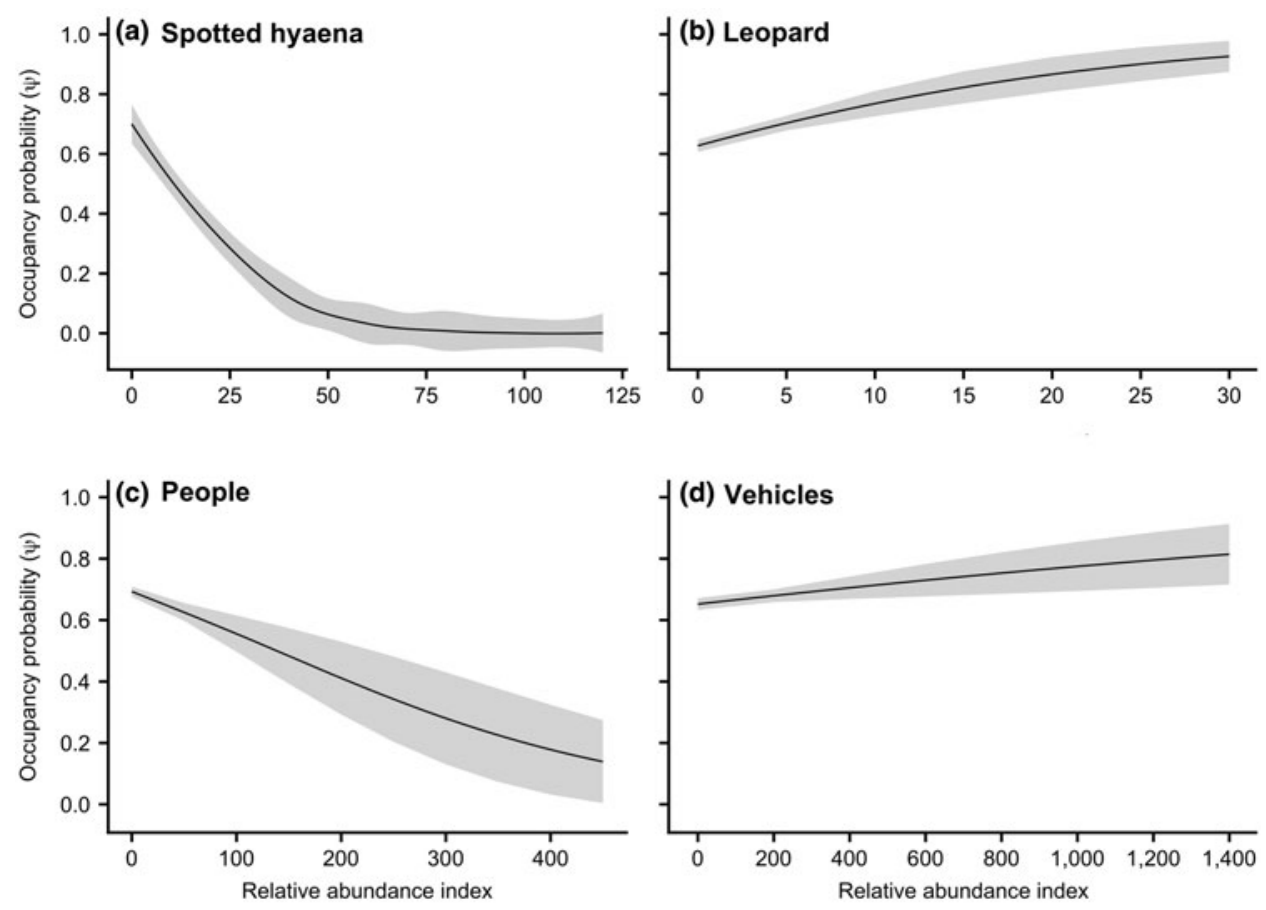

FIG. 2 Relationships between the probability of brown hyaena occupancy and relative abundance index (the number of single capture events per 100 camera-trap days) of (a) the spotted hyaena Crocuta crocuta, (b) the leopard Panthera pardus, (c) people and (d) vehicles. Shaded areas represent $95 \%$ confidence intervals.

People in vehicles are drawn to sightings of iconic animals, which could be more likely to occur in areas with preferable conditions for brown hyaenas (e.g. areas where human foot traffic is low and resources are abundant). Vehicle-based ecotourism may also contribute to anti-poaching efforts by providing additional surveillance (Baral, 2013).

Despite the large spatial scale of our study, private land used for farming was underrepresented in our dataset. Management of the analysed survey sites, especially in regards to fencing and supplementary feeding, may differ in unprotected land and we recommend further research to examine how these site-specific factors affect brown hyaena occupancy. Large predators such as spotted hyaenas, lions, cheetahs and African wild dogs have been largely extirpated from much unprotected land in southern Africa (Ray et al., 2005). The absence of these species leaves leopards and brown hyaenas as the only apex predator across much of their shared range. Our results suggest that such conditions promote high brown hyaena occupancy as long as human disturbance is minimized, emphasizing the potential importance of private land for brown hyaena conservation.

Carnivores occurring outside formally protected areas are particularly vulnerable to anthropogenic threats (Balme et al., 2010). With a severe decline in leopards already underway globally (Jacobson et al., 2016), conservation measures need to be established to preserve leopards on private land; our results suggest this will also aid brown hyaena conservation across their range. We thus recommend a holistic, multi-species approach that considers the entire large carnivore guild, rather than a single-species approach. Broader approaches to conservation that encompass multiple species or even entire landscapes are becoming increasingly popular, such as the focal species paradigm (Lindenmayer et al., 2014), which utilizes a suite of species, each of which is used to define various attributes in a landscape (Lambeck, 1997).

Areas with low human disturbance are also vital for brown hyaena conservation and should be prioritized for protection. This is easier to facilitate in protected areas, but outside protected areas private land used for wildlife farming tends to have lower levels of human disturbance than land used for livestock farming (Thorn et al., 2012). Wildlife farms provide a plentiful prey base for predators and abundant scavenging opportunities for brown hyaenas, both naturally and through meat discarded after commercial hunts. Scavengers such as brown hyaenas provide important ecosystem services to these areas through their feeding habits (Beasley et al., 2015). Despite the potential for wildlife farms to act as refuges for brown hyaenas, intolerance towards predators and subsequent persecution can be high on wildlife farms (Pitman et al., 2017b). Greater public education about the value of brown hyaenas and their dietary habits is therefore required.

Survey site and effort influenced brown hyaena detection probability. The effect of site variability on detection can be the product of a multitude of variables, including the density of brown hyaenas, animal behaviour, thickness of vegetation and seasonality (Tan et al., 2017). Although there are advantages of broad-scale studies, inconsistences in probability of detection highlight the importance of fine-scale or regional-scale surveys in conservation and incorporating a variety of knowledge sources, especially when constructing 
locally specific management approaches (Raymond et al., 2010).

Finally, our case study is an example of how a collaborative approach that combines small-scale datasets and utilizes bycatch data can be a powerful tool to fit occupancy models at broader spatial scales. This approach can inform conservation management strategies at national or global scale when applied to species with a restricted international area of occupancy such as the brown hyaena. With limits of time, funding and resources challenging ecological research, this recycle and repurpose approach to data extends the potential of camera trapping to inform high-level wildlife management strategies. We suggest the development of better information sharing platforms to enable the collaborations necessary to share camera-trap data and conduct research at this scale. These platforms need to extend beyond the boundaries of protected areas, where research is frequently conducted. Collaborative data sharing from camera-trap owners outside protected areas will not only provide vital distribution and occupancy information but will also strengthen dialogues and relationships between conservation organizations, scientists and private landowners.

Acknowledgements We acknowledge the financial assistance of the National Research Foundation and the Durham University COFUND research fellowship programme towards this study. Opinions expressed, and conclusions, are those of the authors and are not necessarily to be attributed to the National Research Foundation. Panthera funded research at 24 survey sites. At these sites we thank the Limpopo Department of Economic Development, Environment and Tourism, Ezemvelo KwaZulu-Natal Wildlife, the numerous reserves, Wildlife ACT, Wildlife and Ecological Investments, and Siyafunda Conservation. This research forms part of Camera CATalogue (cameracatalogue.org), a division of Panthera's integrated data management system. We are grateful to Zooniverse (zooniverse.org), their staff, and the 12,500 citizen scientists for their contributions in classifying camera-trap data. Data collected by JC at Mountain Zebra National Park was funded by the National Research Foundation and Rhodes University. STW is funded by a University of Venda postdoctoral grant.

Author contributions Study design: KSW, DMP, RTP, GAB, RAH; fieldwork: RTP, GKHM, GW, JC, KSW, STW; data analysis: KSW; writing: all authors.

\section{Conflicts of interest None.}

Ethical standards This research abided by the Oryx guidelines on ethical standards.

\section{References}

Ahumada, J.A., O’Brien, T.G., Mugerwa, B. \& Hurtado, J. (2016) Camera trapping as a monitoring tool at national and global levels. In Camera Trapping for Wildife Research (eds F. Rovero \& F. Zimmermann), pp. 196-218. Pelagic Publishing, Exeter, UK.

Balme, G.A., Slotow, R. \& Hunter, L.T.B. (2010) Edge effects and the impact of non-protected areas in carnivore conservation: leopards in the Phinda-Mkhuze Complex, South Africa. Animal Conservation, 13, 315-323.

BARAL, A.N. (2013) Impacts of wildlife tourism on poaching of greater one-horned rhinoceros (Rhinoceros unicornis) in Chitwan National Park, Nepal. MSc thesis. Lincoln University, Lincoln, UK.

Barbieri, M.M. \& Berger, J.O. (2004) Optimal predictive model selection. The Annals of Statistics, 32, 870-897.

Beasley, J.C., Olson, Z.H. \& DeVAult, T.L. (2015) Ecological role of vertebrate scavengers. In Carrion Ecology, Evolution, and their Applications (eds M.E. Benbow, J.K. Tomberlin \& A.M. Tarone), pp. 107-121. CRC Press, Boca Raton, USA.

Bischof, R., Brøseth, H. \& Gimenez, O. (2016) Wildlife in a politically divided world: insularism inflates estimates of brown bear abundance. Conservation Letters, 9, 122-130.

Broms, K.M., Johnson, D.S., AltwegG, R. \& Conquest, L.L. (2014) Spatial occupancy models applied to atlas data show southern ground hornbills strongly depend on protected areas. Ecological Applications, 24, 363-374.

Burnham, K.P. \& Anderson, D.R. (1998) Model Selection and Inference: A Practical Information-Theoretic Approach. Springer, New York, USA.

Cardillo, M., Purvis, A., Sechrest, W., Gittleman, J.L., Bielby, J. \& MACE, G.M. (2004) Human population density and extinction risk in the world's carnivores. PLOS Biology, 2, 909-914.

Carter, N.H., Shrestha, B.K., Karki, J.B., Pradhan, N.M.B. \& LiU, J.G. (2012) Coexistence between wildlife and humans at fine spatial scales. Proceedings of the National Academy of Sciences of the United States of America, 109, 15360-15365.

Chundawat, R.S., Sharma, K., Gogate, N., Malik, P.K. \& Vanak, A.T. (2016) Size matters: scale mismatch between space use patterns of tigers and protected area size in a Tropical Dry Forest. Biological Conservation, 197, 146-153.

Department of Environmental Affairs Republic of South AfricA (2015) DEA National Landcover (TIFF) 2015. bgis.sanbi.org/ SpatialDataset/Detail/496 [accessed 2 July 2019].

Edwards, S., Cooper, S., Uiseb, K., Hayward, M., Wachter, B. \& Melzheimer, J. (2018) Making the most of by-catch data: assessing the feasibility of utilising non-target camera trap data for occupancy modelling of a large felid. African Journal of Ecology, 56, 885-894.

Estes, R.D. (1991) The Behavior Guide to African Mammals Including Hoofed Mammals, Carnivores, Primates. University of California Press, Berkeley, USA.

Fiske, I. \& Chandler, R. (2011) Unmarked: an $R$ package for fitting hierarchical models of wildlife occurrence and abundance. Journal of Statistical Software, 43, 1-23.

Gavashelishvili, A. \& Lukarevskiy, V. (2008) Modelling the habitat requirements of leopard Panthera pardus in west and Central Asia. Journal of Applied Ecology, 45, 579-588.

Gelfand, A.E. \& Ghosh, S.K. (1998) Model choice: a minimum posterior predictive loss approach. Biometrika, 85, 1-11.

Gittleman, J.L., Funk, S.M., Macdonald, D.W. \& Wayne, R.K. (2001) Why 'carnivore conservation'? In Carnivore Conservation (eds J.L. Gittleman, S.M. Funk, D.W. Macdonald \& R.K. Wayne), pp. 1-7. Cambridge University Press, Cambridge, UK.

HARIHAR, A. \& PANDAV, B. (2012) Influence of connectivity, wild prey and disturbance on occupancy of tigers in the human-dominated western Terai Arc Landscape. PLOS ONE, 7, e40105.

Hayward, M. (2006) Prey preferences of the spotted hyaena (Crocuta crocuta) and degree of dietary overlap with the lion (Panthera leo). Journal of Zoology, 270, 606-614.

Henschel, P., Hunter, L.T.B., Coad, L., Abernethy, K.A. \& Múhlenberg, M. (2011) Leopard prey choice in the Congo basin rainforest suggests exploitative competition with human bushmeat hunters. Journal of Zoology, 285, 11-20. 
Hughes, J. \& Haran, M. (2013) Dimension reduction and alleviation of confounding for spatial generalized linear mixed models. Journal of the Royal Statistical Society: Series B (Statistical Methodology), 75, 139-159.

Jacobson, A.P., Gerngross, P., Lemeris JR, J.R., Schoonover, R.F., Anco, C., Breitenmoser-Würsten, C. et al. (2016) Leopard (Panthera pardus) status, distribution, and the research efforts across its range. PeerJ, 4, e1974.

Jennelle, C.S., Runge, M.C. \& MacKenzie, D.I. (2002) The use of photographic rates to estimate densities of tigers and other cryptic mammals: a comment on misleading conclusions. Animal Conservation, 5, 119-120.

Johnson, D.S. (2015) Package 'stocc': an $R$ package to fit a spatial occupancy model via Gibbs sampling. rdrr.io/cran/stocc [accessed 16 December 2019].

Johnson, D.S., Conn, P.B., Hooten, M.B., Ray, J.C. \& Pond, B.A. (2013) Spatial occupancy models for large data sets. Ecology, 94, 801-808.

Karanth, K.U., Gopalaswamy, A.M., Kumar, N.S., Vaidyanathan, S., Nichols, J.D. \& MacKenZie, D.I. (2011) Monitoring carnivore populations at the landscape scale: occupancy modelling of tigers from sign surveys. Journal of Applied Ecology, 48, 1048-1056.

Kent, V.T. \& Hill, R.A. (2013) The importance of farmland for the conservation of brown hyaena, Parahyaena brunnea. Oryx, 47, 431-440.

Kesch, K.M., Bauer, D.T. \& Loveridge, A.J. (2013) Undermining game fences: who is digging holes in Kalahari sands? African Journal of Ecology, 52, 144-150.

Kesch, M.K., B Auer, D.T. \& Loveridge, A.J. (2015) Break on through to the other side: the effectiveness of game fencing to mitigate humanwildlife conflict. African Journal of Wildlife Research, 45, 76-88.

KUHN, B.F. (2014) A preliminary assessment of the carnivore community outside Johannesburg, South Africa. South African Journal of Wildlife Research, 44, 95-98.

LAMBECK, R.J. (1997) Focal species: a multi-species umbrella for nature conservation. Conservation Biology, 11, 849-856.

Latimer, A.M., Wu, S., Gelfand, A.E. \& Silander, J.A. (2006) Building statistical models to analyze species distributions. Ecological Applications, 16, 33-50.

LEGENDRE, P. (1993) Spatial autocorrelation: trouble or new paradigm? Ecology, 74, 1659-1673.

Lin, D., Foster, D.P. \& UnGar, L.H. (2011) VIF regression: a fast regression algorithm for large data. Journal of the American Statistical Association, 106, 232-247.

Lindenmayer, D., Lane, P., Westgate, M., Crane, M., Michael, D., OKada, S. \& Barton, P. (2014) An empirical assessment of the focal species hypothesis. Conservation Biology, 28, 1594-1603.

Linkie, M., Dinata, Y., Nugroho, A. \& Haidir, I.A. (2007) Estimating occupancy of a data deficient mammalian species living in tropical rainforests: sun bears in the Kerinci Seblat region, Sumatra. Biological Conservation, 137, 20-27.

Linkie, M., Guillera-Arroita, G., Smith, J., Ario, A., Bertagnolio, G., Cheong, F. et al. (2013) Cryptic mammals caught on camera: assessing the utility of range wide camera trap data for conserving the Endangered Asian tapir. Biological Conservation, 162, 107-115.

Long, R.A., Donovan, T.M., MacKay, P., Zielinski, W.J. \& BuZas, J.S. (2011) Predicting carnivore occurrence with noninvasive surveys and occupancy modeling. Landscape and Ecological Engineering, 26, 327-340.

MacKenzie, D.I. \& Bailey, L.L. (2004) Assessing the fit of site-occupancy models. Journal of Agricultural, Biological, and Environmental Statistics, 9, 300-318.
MacKenzie, D.I. \& Royle, J.A. (2005) Designing occupancy studies: general advice and allocating survey effort. Journal of Applied Ecology, 42, 1105-1114.

MacKenzie, D.I., Nichols, J.D., Lachman, G.B., Droege, S., Royle, J.A. \& Langtimm, C.A. (2002) Estimating site occupancy rates when detection probabilities are less than one. Ecology, $83,2248-2255$.

MacKenzie, D.I., Nichols, J.D., Royle, J.A., Pollock, K.P., Bailey, L.L. \& Hines, J.E. (2006) Occupancy Estimation and Modeling: Inferring Patterns and Dynamics of Species Occurrence. Academic Press, Oxford, UK.

Mann, G.K., O'Riain, M.J. \& Parker, D.M. (2015) The road less travelled: assessing variation in mammal detection probabilities with camera traps in a semi-arid biodiversity hotspot. Biodiversity and Conservation, 24, 531-545.

Marker, L., Dickman, A.J., Mills, M.G.L. \& Macdonald, D.W. (2010) Cheetahs and ranchers in Namibia: a case study. In Biology and Conservation of Wild Felids (eds D.W. Macdonald \& A.J. Loveridge), pp. 353-372. Oxford University Press, Oxford, UK.

Martins, Q. \& Harris, S. (2013) Movement, activity and hunting behaviour of leopards in the Cederberg Mountains, South Africa. African Journal of Ecology, 51, 571-579.

MaUde, G. (2005) The comparative ecology of the brown hyaena (Hyaena brunnea) in Makgadikgadi National Park and a neighbouring community cattle area in Botswana. MSc thesis. University of Pretoria, Pretoria, South Africa.

Maude, G. \& Mills, M.G.L. (2005) The comparative feeding ecology of the brown hyaena in a cattle area and a national park in Botswana. South African Journal of Wildlife Research, 35, 201-214.

McCallum, J. (2013) Changing use of camera traps in mammalian field research: habitats, taxa and study types. Mammal Review, 43, 196-206.

Meredith, M. (2008) Analyzing camera trap data with PRESENCE. In Problem-solving in Conservation Biology and Wildlife Managment (eds J.P. Gibbs, M.L. Hunter Jr. \& E.J. Sterling), pp. 105-124. Blackwell Publishing, Malden, USA.

Miller, D.A.W. \& Grant, E.H.C. (2015) Estimating occupancy dynamics for large-scale monitoring networks: amphibian breeding occupancy across protected areas in the northeast United States. Ecology and Evolution, 5, 4735-4746.

Miller, J.R., Pitman, R.T., Mann, G.K., Fuller, A.K. \& Balme, G.A. (2018) Lions and leopards coexist without spatial, temporal or demographic effects of interspecific competition. Journal of Animal Ecology, 87, 1709-1726.

Mills, M.G.L. (1984) The comparative behavioural ecology of the brown hyaena Hyaena brunnea and the spotted hyaena Crocuta crocuta in the southern Kalahari. Koedoe, 27, 237-247.

Mills, M.G.L. (1990) Kalahari Hyaenas: Comparative Behavioral Ecology of Two Species. Unwin Hyman, London, UK.

MilLs, M.G.L. (2015) Living near the edge: a review of the ecological relationships between large carnivores in the arid Kalahari. South African Journal of Wildlife Research, 45, 127-137.

Mills, M.G.L. \& Gorman, M.L. (1997) Factors affecting the density and distribution of wild dogs in the Kruger National Park. Conservation Biology, 11, 1397-1406.

Mills, M.G.L. \& Hofer, H. (1998) Hyaenas: Status Survey and Conservation Action Plan, IUCN/Species Survival Commission Hyaena Specialist Group, Gland, Switzerland.

Mills, M.G.L. \& Mills, M.E.J. (1978) The diet of the brown hyaena Hyaena brunnea in the southern Kalahari. Koedoe, 21, 125-149.

Mills, M.G.L. \& Mills, M.E.J. (1982) Factors affecting the movement patterns of brown hyaenas, Hyaena brunnea, in the southern Kalahari. South African Journal of Wildife Research, 12, 111-117. 
Negrões, N., Sarmento, P., Cruz, J., Eira, C., Revilla, E., FONSECA, C. et al. (2010) Use of camera-trapping to estimate puma density and influencing factors in central Brazil. Journal of Wildlife Management, 74, 1195-1203.

O’Brien, T.G., Kinnaird, M.F. \& Wibisono, H.T. (2003) Crouching tigers, hidden prey: Sumatran tiger and prey populations in a tropical forest landscape. Animal Conservation, 6, 131-139.

O'Connell, A.F. \& BAiley, L.L. (2011) Inference for occupancy and occupancy dynamics. In Camera Traps in Animal Ecology: Methods and Analyses (eds A.F. O'Connell, J.D. Nichols \& K.U. Karanth), pp. 191-205. Springer, New York, USA.

Pitman, R.T., Fattebert, J., Williams, S.T., Williams, K.S., Hill, R.A., Hunter, L.T.B. et al. (2017a) Cats, connectivity and conservation: incorporating datasets and integrating scales for wildlife management. Journal of Applied Ecology, 54, 1687-1698.

Pitman, R.T., Fattebert, J., Williams, S.T., Williams, K.S., Hill, R.A., Hunter, L.T.B. et al. (2017b) The conservation costs of game ranching. Conservation Letters, 10, 403-413.

QGIS Development Team (2018) QGIS Geographic Information System. Open Source Geospatical Foundation Project. qgis.org [accessed 1 July 2019].

R Development Core Team (2017) R: a language and environment for statistical computing. The R Foundation for Statistical Computing, Vienna, Austria.

Ray, J.C., Hunter, L.T.B. \& Zigouris, J. (2005) Setting Conservation and Research Priorities for Larger African Carnivores. Working paper number 24. Wildlife Conservation Society, New York, USA.

Raymond, C.M., FAzey, I., Reed, M.S., Stringer, L.C., Robinson, G.M. \& Evely, A.C. (2010) Integrating local and scientific knowledge for environmental management. Journal of Environmental Management, 91, 1766-1777.

Ripple, W.J., Estes, J.A., Beschta, R.L., Wilmers, C.C., Ritchie, E.G., Hebblewhite, M. et al. (2014) Status and ecological effects of the world's largest carnivores. Science, 343, 1241484.

Rota, C.T., Fletcher, R.J., Dorazio, R.M. \& Betts, M.G. (2009) Occupancy estimation and the closure assumption. Journal of Applied Ecology, 46, 1173-1181.

Schuette, P., Wagner, A.P., Wagner, M.E. \& Creel, S. (2013) Occupancy patterns and niche partitioning within a diverse carnivore community exposed to anthropogenic pressures. Biological Conservation, 158, 301-312.

Sillero-Zubiri, C. \& Laurenson, M.K. (2001) Interactions between carnivores and local communities: conflict or co-existence? In Carnivore Conservation (eds J.L. Gittleman, S.M. Funk, D.W. Macdonald \& R.K. Wayne), pp. 282-312. Cambridge University Press, Cambridge, UK.

Sing, T., Sander, O., Beerenwinkel, N. \& Lengauer, T. (2005) ROCR: visualizing classifier performance in R. Bioinformatics, 21, 3940-3941.

Singh, R., Qureshi, Q., Sankar, K., Krausman, P.R., Goyal, S.P. \& Nicholson, K.L. (2014) Population density of striped hyenas in relation to habitat in a semi-arid landscape, western India. Acta Theriologica Sinica, 59, 521-527.

Skinner, D. \& Chimimba, T. (2005) The Mammals of the Southern African Subregion. Cambridge University Press, Cambridge, UK.

Stein, A.B., Fuller, T.K. \& Marker, L.L. (2013) Brown hyaena feeding ecology on Namibian farmlands. South African Journal of Wildlife Research, 43, 27-32.

Steinmetz, R., Seuaturien, N. \& Chutipong, W. (2013) Tigers, leopards, and dholes in a half-empty forest: assessing species interactions in a guild of threatened carnivores. Biological Conservation, $163,68-78$.

Strampelli, P., Andresen, L., Everatt, K.T., Somers, M.J. \& Rowcliffe, J.M. (2018) Habitat use responses of the African leopard in a human-disturbed region of rural Mozambique. Mammalian Biology, 89, 14-20.

Swanepoel, L. (2008) Ecology and conservation of leopards, Panthera pardus, on selected game ranches in the Waterberg Region, Limpopo, South Africa. MSc thesis. University of Pretoria, Pretoria, South Africa.

Tan, C.K.W., Rocha, D.G., Clements, G.R., Brenes-Mora, E., Hedges, L., Kawanishi, K. et al. (2017) Habitat use and predicted range for the mainland clouded leopard Neofelis nebulosa in Peninsular Malaysia. Biological Conservation, 206, 65-74.

Thorn, M., Scott, D.M., Green, M., Bateman, P.W. \& Cameron, E.Z. (2009) Estimating brown hyaena occupancy using baited camera traps. South African Journal of Wildlife Research, 39, 1-10.

Thorn, M., Green, M., Dalerum, F., Bateman, P.W. \& Scott, D.M. (2012) What drives human-carnivore conflict in the North West Province of South Africa? Biological Conservation, 150, 23-32.

Treves, A., Mwima, P., Plumptre, A.J. \& Isoke, S. (2010) Camera-trapping forest-woodland wildlife of western Uganda reveals how gregariousness biases estimates of relative abundance and distribution. Biological Conservation, 143, 521-528.

Trolliet, F., Huynen, M., Vermeulen, C. \& Hambunkers, A. (2014) Use of camera traps for wildlife studies. A review. Biotechnologie Agronomie Société et Environnement, 18, 446-454.

UNEP-WCMC (2018) Protected Area Profile for South Africa from the World Database of Protected Areas, June 2018. protectedplanet. net [accessed 6 June 2018].

Wang, T., Royle, J.A., Smith, J.L., Zou, L., LÜ, X., Li, T. et al. (2018) Living on the edge: opportunities for Amur tiger recovery in China. Biological Conservation, 217, 269-279.

Welch, R.J., Tambling, C.J., Bissett, C., Gaylard, A., Muller, K., Slater, K. et al. (2016) Brown hyena habitat selection varies among sites in a semi-arid region of southern Africa. Journal of Mammalogy, 97, 473-482.

Wiesel, I. (2015) Parahyaena brunnea. In The IUCN Red List of Threatened Species 2015: e.T10276A82344448. dx.doi.org/10.2305/ IUCN.UK.2015-4.RLTS.T10276A82344448.en [accessed 10 April 2019].

Williams, K.S. (2017) Human-brown hyaena relationships and the role of mountainous environments as refuges in a postcolonial landscape. PhD thesis. Durham University, Durham, UK.

Williams, K.S., Williams, S.T., Fitzgerald, L.E., Sheppard, E.C. \& HilL, R.A. (2018) Brown hyaena and leopard diets on private land in the Soutpansberg Mountains, South Africa. African Journal of Ecology, 56, 1021-1027.

Winterbach, H.E.K., Winterbach, C.W., Somers, M.J. \& HaYward, M.W. (2013) Key factors and related principles in the conservation of large African carnivores. Mammal Review, $43,89-110$.

Yarnell, R., Richmond-Coggan, L., Bussiere, E., Williams, K., Bissett, C., Welch, R. \& Wiesel, I. (2016) A conservation assessment of Parahyaena brunnea. In The Red List of Mammals of South Africa, Swaziland and Lesotho (eds M.F. Child, L. Roxburgh, E. Do Linh San, D. Raimondo \& H. Davies-Mostert), pp. 1-8. South African National Biodiversity Institute and Endangered Wildlife Trust, Johannesburg, South Africa. 